\title{
Lymphoma of Ovary: A Primary Extra-nodal Manifestation
}

\author{
Joshi AP, Chitrakar NS, Shrestha I \\ Department of Obstetrics and Gynaecology, Civil Service Hospital of Nepal, Minbhawan, Kathmandu, Nepal
}

Received: January 05, 2015; Accepted: May 12, 2015

Involvement of the ovary by malignant lymphoma is a well-known manifestation of disseminated nodal disease. But, lymphoma as primary manifestation is extremely rare. Here, we report a case of malignant lymphoma which presented as ovarian cancer and managed with surgery and subsequent chemotherapy. A lady of thirty two years presented with features of malignant ovarian tumor. The diagnosis of malignant ovarian lymphoma was made after surgery and histological and immunohistochemical study of the excised tumor. The tumor was classified as diffuse large B-cell lymphoma. The patient was put on chemotherapy and she is on follow-up in disease free-state for last two years.

Keywords: lymphoma; ovary; primary.

\section{INTRODUCTION}

Ovary is the site of pluripotency. So, ovaries are very susceptible to various malignant and benign histopathological tumors. One of the rare forms of tumor that arise in ovary is lymphoma. Lymphoma can arise de novo or as a part of systemic disease. Common form of lymphoma in ovary is nonHodgkin's type. Primary ovarian non-Hodgkin's lymphoma is very rare accounting $0.5 \%$ of all nonHodgkin's lymphomas and $1.5 \%$ of all ovarian neoplasms. ${ }^{1,2}$ We present a case of non-Hodgkin's lymphoma of the ovary which was managed with surgery and chemotherapy.

\section{CASE}

A lady of thirty two years with two children, regularly menstruating, presented to emergency with complaints of pain lower abdomen for one month which had increased for four days and fever with chills and rigors also for the same duration. There was no significant past medical and surgical as well as family history. Her examination revealed generalized abdominal and fornicial fullness with tenderness however there was no lymphadenopathy.

Her blood investigation including complete blood counts showed no abnormality. Among the tumor markers Cancer Antigen-125 (CA-125) was 236 and

\section{CORRESPONDENCE}

Dr Arun Prasad Joshi

Department of Obstetrics and Gynaecology,

Civil Service Hospital of Nepal, Minbhawan

Email: e_apj2000@yahoo.com

Phone: +977-9841341723
Lactate Dehydrogenase (LDH) was 1636. Contrast enhanced Computerised-Tomography revealed large heterogenously enhancing soft tissue density masses in bilateral parauterine region with ascitis, enhancing omental thickening and retroperitoneal lymphadenopathy. The ascitic fluid for cytology was negative for malignancy and fine needle aspiration cytology of tumor deposit showed chronic inflammatory lesion.

She underwent staging laparotomy with total abdominal hysterectomy, bilateral adnexectomy, omentectomy and peritoneal biopsy and staged as IIIc.

She was found to have straw coloured ascitic fluid around $1000 \mathrm{ml}$ with bilateral ovarian solid tumors, right sided measuring $7 \times 5 \mathrm{~cm}$ and left $5 \times 4 \mathrm{~cm}$ with intact capsule (Figure 1).

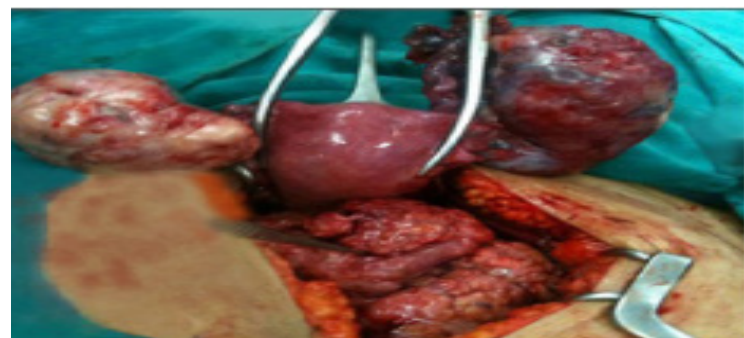

Figure 1. Intra operative finding of uterus bilateral ovarian tumor with involved omentum.

The Omentum was thickened and studded with miliary like deposits and similar deposits were present in bowel, bladder, liver, under surface of diaphragm. Both parietal and visceral peritoneum were thickened. On gross examination, there were bilateral solid ovarian tumors with areas of cystic degeneration and omental caking (Figure 2 and 3). 


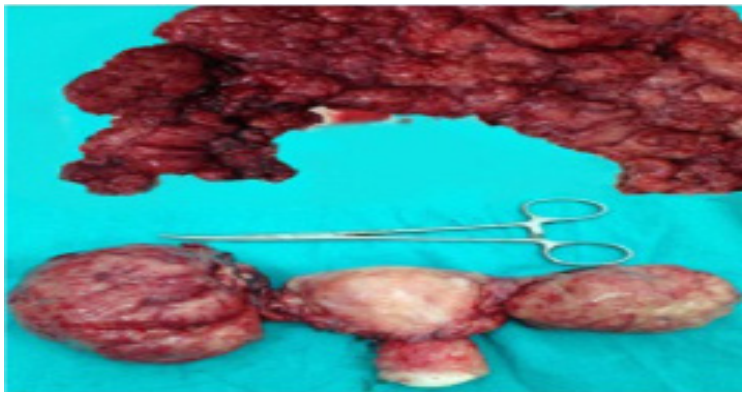

Figure 2. Excised tissue of bilateral ovarian tumor with omentum.

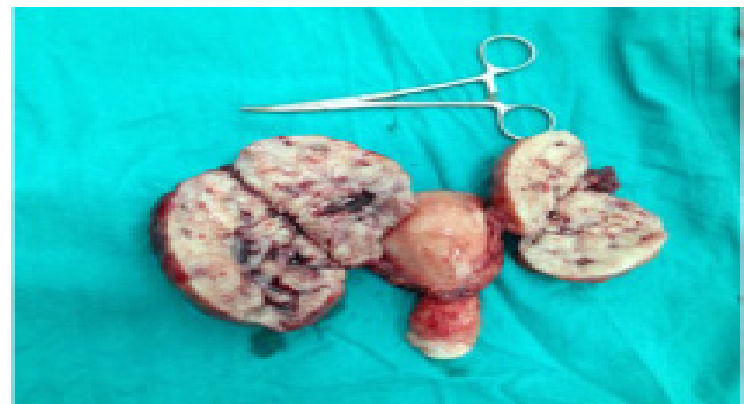

Figure 3. Cut section of bilateral ovarian tumor.

The excised tissue sent for histopathological examination was consistent with bilateral ovarian nonHodgkin's lymphoma with extragonadal involvement (peritoneal biopsy and omentum were positive for tumor). Immunohistochemistry of the same showed Leucocyte common antigen (LCA), CD20 and Bcl-6 being positive favoring diffuse B-cell non-Hodgkin's lymphoma.

Her bone marrow aspiration done after surgery showed normal hematopoiesis with no abnormal cells.

The patient received six cycles of Cyclophosphamide, Hydroxydaunorubicin (doxorubicin or adriamycin), Oncovin (vincristine), Prednisone (CHOP) regimen. Follow-up Computerised Tomography (CT) scan done after six months of treatment showed no signs of recurrence.

\section{COMMENT}

Lymphoma is a rare tumor of the ovary and its presence most commonly represents involvement in overt systemic disease, almost always of nonHodgkin's type. ${ }^{3,4}$ The diffuse large B-cell lymphoma appears to be the most common one. ${ }^{2}$ Lymphoma of ovary can be divided into primary and secondary. It is important to separate one from the other because there is considerable evidence that primary extranodal lymphoma tends to run a less aggressive course than does the nodal one. ${ }^{5,6}$ The 5 year survival for extra-nodal is $80 \%$ whereas secondary malignant lymphoma is only $33 \% .^{7}$ Fox et $\mathrm{al}^{8}$ suggested criteria for diagnosing primary ovarian lymphoma 1) Tumor is confined to ovary, regional lymph nodes or adjunctive organs at the time of diagnosis 2) the peripheral blood and the bone marrow should not contain any abnormal cells 3) The lymphomateous lesions that occur at the sites remote from the ovary, at least several months should have elapsed between appearance of ovarian and extra ovarian lesions. In our case there was no obvious lymphadenopathy (except retroperitoneal) and no atypical cells in peripheral blood at presentation and post-treatment follow-up CT scan favoring the diagnosis of primary ovarian lymphoma. However, there is always an argument regarding this when there is involvement of omentum and peritoneum at the time of surgery as seen in our case. ${ }^{1,9}$

Majority of primary ovarian lymphomas present with pelvic complaint; some cases present with ascitis and raised CA- $125^{10}$ which were also present in this case.

The use of chemotherapy is based on the principle that ovarian lymphoma must be considered as a localized manifestation of systemic disease. ${ }^{8}$ The appropriate chemotherapy regimen is CHOP as similar to nodal non-Hodgkin's lymphomas.

Our patient was also treated with total abdominal hysterectomy and bilateral adnexectomy and omentectomy followed by six cycles of CHOP regimen. At present she is doing well. Considering the way she presented to us, findings at surgery, blood and bone marrow investigations and respond to the treatment modalities, primary ovarian lymphoma is more likely entity rather than secondary to systemic nodal non-Hodgkin's lymphoma of ovary.

In conclusion, lymphoma of ovary is a rare manifestation. Primary extra-nodal manifestation in ovary lymphoma should also be considered as a differential diagnosis when a middle aged lady presents with features of advanced ovarian cancer.

\section{DISCLOSURE}

The authors report no conflicts of interest in this work. No violation of human rights and safety.

Funding: Nil 


\section{REFERENCES}

1. Elharroudi T, Ismaili N, Errihani H, Jalil A. Primary lymphoma of the ovary. J Cancer Res Ther. 2008;4:195-6.

2. Dimopoulos MA, Daliani D, Pugh W, Gershenson D, Cabanillas F, Sarris AH, et al. Primary ovarian non-Hodgkin's lymphoma: Outcome after treatment with combination chemotherapy. Gynecol Oncol. 1997;64:446-50.

3. Monterrosso V, Jaffe ES, Merino MJ, Medeiros LJ. Malignant lymphomas involving the ovary: A clinicopathologic analysis of 39 cases. Am J Surg Pathol. 1993;17:154-70.

4. Memon MA, Ahmed HKN, Langah AA, Shuja J, Mustafa $\mathrm{KA}$, Ahmed I, et al. A case of primary ovarian B-cell nonHodgkin's lymphoma. APMC. 2012;6:102-6.

5. Mastilović K, Jovanović D, Kapicl TI, Kopitović S. Lymphoma Ovarii case survey. Arch Oncol. 2009;17(1-2):278.
6. Ferrozzi F, Tognini G, Bova D, Zuccoli G. Non-Hodgkin's lymphomas of the ovaries: MR findings. J Comput Assis Tomogr. 2000;24:416-20.

7. Dantkale SS, Pandit GA, Joshi SS, Pudale SS. Primary bilateral non-Hodgkin's ovarian lymphoma- a case report. JKIMSU. 2012;1:155-9.

8. Fox H, Langley FA, Govan AD, Hill AS, Bennett $\mathrm{MH}$ Malignant lymphoma presenting as ovarian tumor: A clinicopathologic analysis of 34 cases. Br J Obstet Gynaecol 1998;95:386-90.

9. Yamada T, Iwao N, Kasamatsu H, Mori H. A case of malignant lymphoma of the ovary manifesting like an advanced ovarian cancer. Gynecol Oncol. 2003;90:215-9.

10. Vang R, Medeiros LJ, Warnke RA, Higgins JP, Deavers MT. Ovarian non-Hodgkin's lymphoma: Clinicopathologic study of eight primary cases. Mod Pathol. 2001;14(11):1093-9. 